\title{
Outgrowth Patterns of Mycelial Cord-forming Basidiomycetes from and between Woody Resource Units in Soil
}

\author{
By CHRIS G. DOWSON, ${ }^{1}$ ALAN D. M. RAYNER ${ }^{1 *}$ AND LYNNE BODDY ${ }^{2}$ \\ ${ }^{1}$ School of Biological Sciences, University of Bath, Claverton Down, \\ Bath BA2 $7 A Y, U K$ \\ ${ }^{2}$ Department of Microbiology, University College, Newport Road, \\ Cardiff CF2 ITA, UK
}

(Received 24 May 1985; revised 4 September 1985)

\begin{abstract}
Wood blocks colonized by the basidiomycetes Hypholoma fasciculare and Phanerochaete velutina were placed in plastic trays containing moist unsterilized soil. Both fungi grew out radially from the inoculum blocks in the form of networks of mycelial cords. When a second, uncolonized wood block, or set of wood blocks, was provided as a 'bait' about $5 \mathrm{~cm}$ from the inoculum block, marked changes in the form and growth characteristics of the mycelial network followed contact with the bait. These changes were influenced by the relative size of inoculum and bait and included inhibition of radial extension from the inoculum; stimulation of development of connective mycelium; directed growth responses to the bait; fan-shaped outgrowth with conserved polarity from the bait; eventual regression of non-connective mycelium originating from the inoculum. These effects presumably reflect the capacity of the mycelium to behave as a co-ordinated unit and to economize on biomass when growing between discontinuously supplied resource units.
\end{abstract}

\section{INTRODUCTION}

Physiological studies of the growth of mycelial fungi have largely been made using artificial media in which nutrients are supplied homogeneously. These studies have given rise to the concept that fungal mycelia can be envisaged primarily as collections of independently growing and duplicating units ('hyphal growth units'), each consisting of a hyphal tip together with an unspecified length of hypha (Trinci, 1978, 1979). Although this concept may well be appropriate for many fungi growing under at least initially homogeneous conditions, in nature it is common for nutrient resources to be discontinuously supplied, both in space, as separate resource units, and in time (Cooke \& Rayner, 1984). Under these circumstances there will be pressure on the mycelium for economical discovery, exploitation and allocation of available nutrients, and this might be expected to have a considerable impact on growth patterns and co-ordination of activity (Dowding, 1976, 1981; Watkinson, 1984; Thompson, 1984).

Few attempts have been made to study growth patterns between discontinuously supplied resource units experimentally. One group of fungi which habitually grow in this way are certain wood and litter-rotting species, especially of Basidiomycotina, which form mycelial cords. The latter consist of aggregations of predominantly parallel, longitudinally aligned hyphae, and are often differentiated into a distinct outer crust with a high proportion of wide vessel hyphae within its core (Thompson \& Rayner, 1982a, 1983). They form extensive mycelial systems interconnecting pieces of decaying substratum on the woodland floor (Thompson \& Rayner, 1982a, b, 1983; Thompson, 1984), and their large size and ability to grow directly into non-sterile soil from wood block inocula makes them ideal for experimental studies. Here we report one such study, using Hypholoma fasciculare and Phanerochaete velutina, which are both widespread agents of decay of wood of deciduous trees in contact with the woodland floor in Britain. 


\section{METHODS}

Strains and culture media. Hypholoma fasciculare was isolated from tissue of a fruit body produced on a beech (Fagus sylvatica) log collected from Sallowvallets Inclosure, Forest of Dean, Glos., UK (National Grid reference SO 611145). Phanerochaete velutina was isolated from decayed wood of $F$. sylvatica collected from Farleigh Hungerford Woods, Wilts., UK (ST 795563). Both fungi were routinely cultured on $2 \%(\mathrm{w} / \mathrm{v})$ malt extract agar (MA; $20 \mathrm{~g}$ Munton \& Fison spray malt $\mathrm{A}$ and $15 \mathrm{~g}$ Lab-M agar no. 2 per litre).

Preparation of wood block inocula and baits. Wood blocks approximately $8 \mathrm{~cm}^{3}$ were cut from freshly felled trees (approximately $15 \mathrm{~cm}$ diameter) of $F$. sylvatica from Colerne Woods, near Bath (ST 798725). The blocks were stored at $-18^{\circ} \mathrm{C}$. Before use they were thawed, soaked in sterile distilled water for $3 \mathrm{~h}$, and autoclaved in batches of 40 in foil-covered plastic beakers at $121^{\circ} \mathrm{C}$ for $45 \mathrm{~min}$. The blocks were placed into 2-week-old cultures of $H$. fasciculare or $P$. velutina grown on $500 \mathrm{ml} \mathrm{MA}$ in 2-litre wide-necked flasks and the flasks incubated for 5 or 15 weeks at $20^{\circ} \mathrm{C}$ before removal of the wood blocks as inocula. Blocks incubated for 15 weeks were cut before use into $1 \mathrm{~cm}^{3}$ units.

Experimental procedure. Square $(24 \times 24 \mathrm{~cm})$ lidded plastic bioassay dishes $2 \mathrm{~cm}$ deep (available from Nunc; Gibco, Paisley, UK) were three-quarters filled with a sieved (4 $\mathrm{mm}$ mesh size) sandy loam soil collected from Friary Woods, near Bath (ST 785588). Autoclaved, uncolonized wood blocks ('baits') or washed plastic bottle caps (to serve as controls) were then placed either singly (small baits) or in groups of four (large baits) into the soil $13 \mathrm{~cm}$ diagonally away from one corner of the dish. After $7 \mathrm{~d}$ at $20^{\circ} \mathrm{C}$, to permit equilibration of moisture between baits and soil, either $8 \mathrm{~cm}^{3}$ (large) or $1 \mathrm{~cm}^{3}$ (small) colonized wood blocks were placed $5 \mathrm{~cm}$ away from the baits or controls further along the same diagonal. All experiments were made in triplicate, and the dishes were incubated at $20^{\circ} \mathrm{C}$ inside polythene bags in darkness.

Outgrowth from and between the wood blocks was examined at regular intervals (as indicated in Fig. 6), and patterns visible through the underside of the dishes were recorded directly by photocopying on a Xerox 1045 machine. Radial outgrowth was measured along diagonals extending from the corners of inoculum blocks.

\section{RESULTS}

Xerox records of representative sets of mycelial outgrowth patterns are shown in Figs 1-5. Combined growth data from all the experiments are recorded graphically in Fig. 6.

Outgrowth patterns in control dishes were similar in all cases, irrespective of species and inoculum size, in that a persistent, symmetric radiating system was established which reached the edge of the dishes after about $25-30 \mathrm{~d}$ for $P$. velutina and $50 \mathrm{~d}$ for $H$. fasciculare (Fig. 1). The only important deviation from this pattern was the limitation of extension after approximately $35 \mathrm{~d}$ by $H$. fasciculare extending from small inoculum blocks (Fig. $6 b$ ).

By contrast, marked changes in the form and growth characteristics of the mycelium occurred in response to contact with baits, and furthermore these changes were influenced by the relative sizes of inocula and baits, and by the fungal species concerned (Figs 2-5).

Contact with the baits was made by $P$. velutina after $15 \mathrm{~d}$ and by $H$. fasciculare after $22 \mathrm{~d}$. The first visible effects of contact, which in some cases appeared to follow curvature of mycelial cords (e.g. Fig. 3), were the production from the cords of fan-shaped systems of effuse mycelium spreading over the baits. Associated with this was a virtually immediate thickening of the connective cords. During the following days there was an obvious cessation of radial extension and eventual regression of the non-connective remainder of the mycelial front of most of the parent colonies (Fig. 6). Two important exceptions to this pattern were seen with P. velutina. Firstly, those systems growing from large inocula continued to extend at the same rate as controls (Fig. 6). Secondly, with small inocula after contact had been made with the baits, some cords not initially growing towards the bait continued to extend to the edge of the dish, and then apparently redirected towards the bait before eventually making contact and becoming firmly established after $70 \mathrm{~d}$ (Figs $5 d-f$ and $6 d$ ).

Cessation of extension in the case of $H$. fasciculare grown from large inocula was clearly associated with a change from a regular colony margin (Fig. $2 c$ ) to an irregular colony margin (Fig. 2d).

Regression of the non-connective parent colony mycelium was also strongly correlated with emergence of new outgrowth from the baits (Fig. 6). In $H$. fasciculare this renewed outgrowth was in the form of fan-shaped sectors of mycelium, and was always away from the inoculum block, hence conserving the polarity of the original system. There was less regression of mycelia from large inoculum blocks than from small ones: here numerous anastomoses were visible 

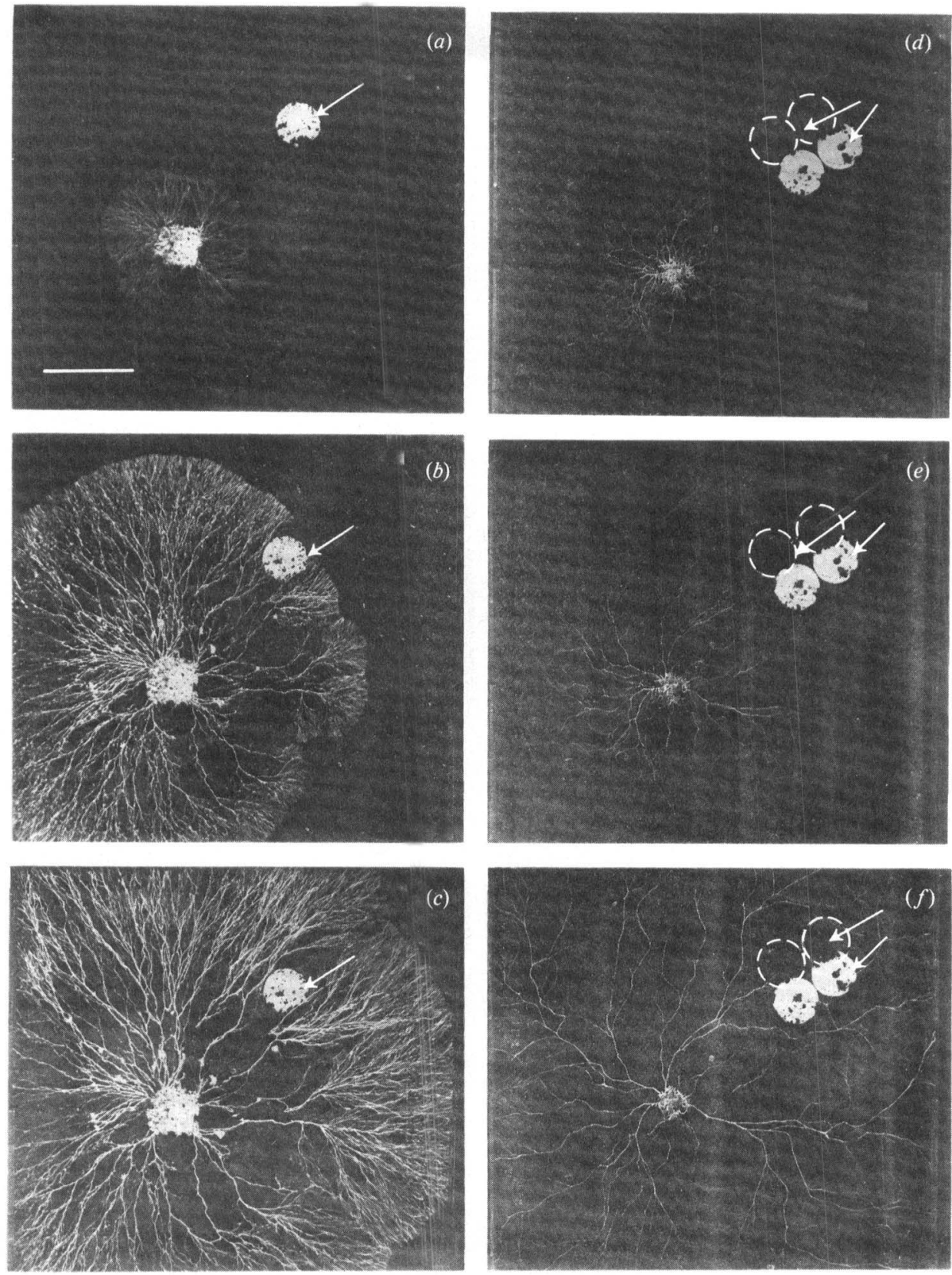

Fig. 1. Outgrowth patterns in control dishes of $H$. fasciculare $(a-c)$ after $(a) 20 \mathrm{~d} ;(b) 51 \mathrm{~d} ;(c) 68 \mathrm{~d}$; and $P$. velutina $(d-f)$, after $(d) 8 \mathrm{~d} ;(e) 12 \mathrm{~d} ;(f) 44 \mathrm{~d}$. Bar represents $4 \mathrm{~cm}$. Arrows indicate position of single bottle caps in $(a-c)$ and groups of four (some obscured by soil) in $(d-f)$. In this and following figures (i.e. Figs 2-5) the left- and right-hand margins of the photographs coincide with, or extend slightly beyond, the edge of the dishes.

$2 e, f)$. Outgrowth of $P$. velutina from large baits (hence small inocula) was similar to that seen with $H$. fasciculare except that the fans of $P$. velutina were more diffuse and showed rather less polarity (Fig. 5). However, outgrowth from small baits (hence large inocula) was by contrast minimal and merged directly with mycelium emanating from inocula, which, as mentioned previously, had shown no signs of cessation of extension or regression (Fig. 3). 

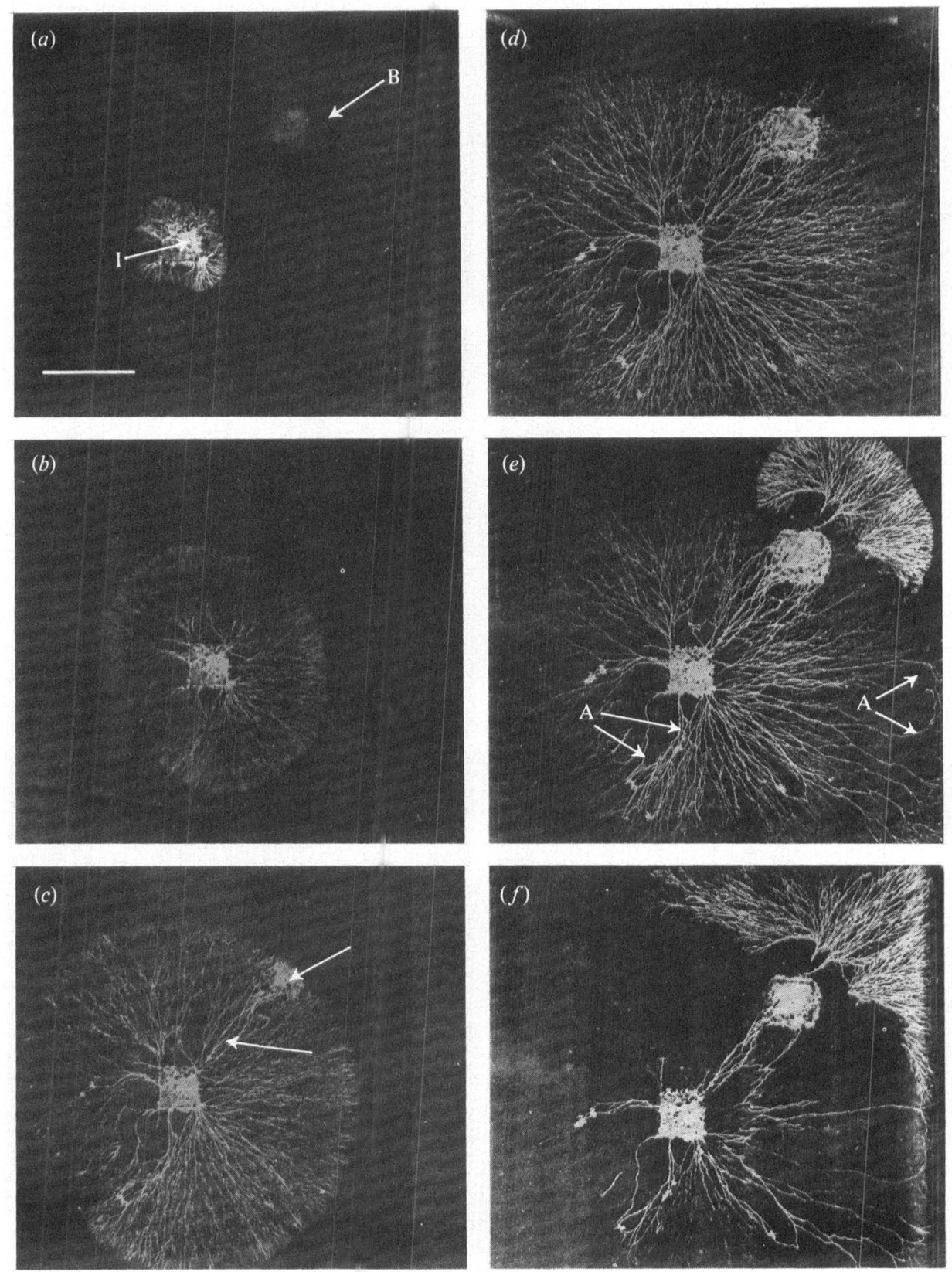

Fig. 2. Outgrowth pattern of $H$. fasciculare from a large inoculum (I) and its response to contact with an equally sized bait (B) after $(a) 8 \mathrm{~d} ;(b) 20 \mathrm{~d} ;(c) 31 \mathrm{~d}$, showing the regular margin present on contact with the bait, and thickening of connective cords (arrowed); (d) $51 \mathrm{~d}$, showing irregular morphology at the edge of the mycelium; (e) $68 \mathrm{~d}$, showing outgrowth from the bait, regression of non-connective mycelium, and position of anastomoses (A) between cords; $(f) 85 \mathrm{~d}$. Bar represents $4 \mathrm{~cm}$. 

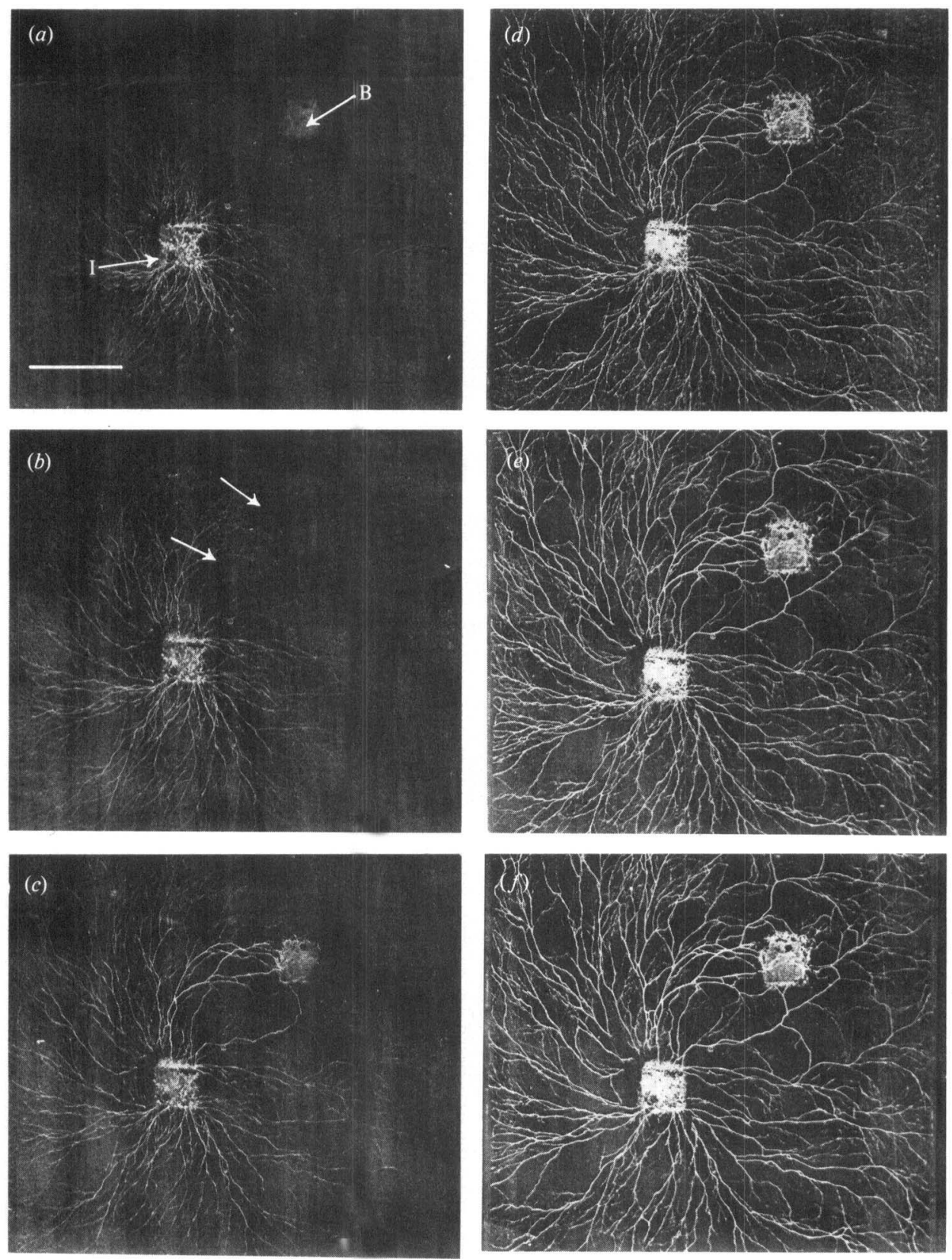

Fig. 3. Outgrowth pattern of P. velutina from a large inoculum (I) and its response to contact with an equally sized bait (B) after (a) $12 \mathrm{~d}$; (b) $20 \mathrm{~d}$, arrows indicate curvature of cords towards the bait; (c) $26 \mathrm{~d} ;(d) 44 \mathrm{~d} ;(e) 62 \mathrm{~d} ;(f) 77 \mathrm{~d}$, showing no regression of non-connective mycelium. Bar represents $4 \mathrm{~cm}$. 

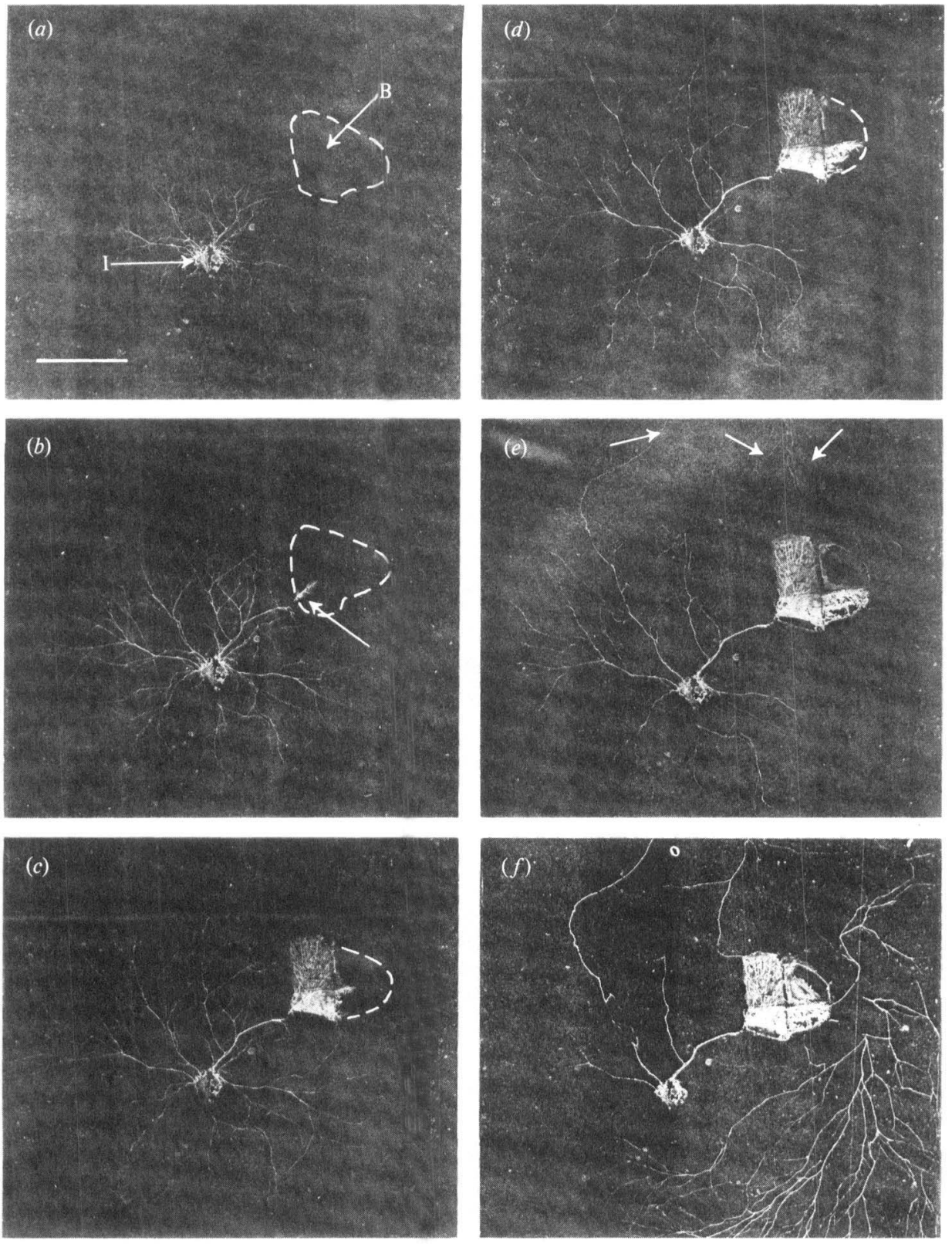

Fig. 4. Outgrowth pattern of $H$. fasciculare from a small inoculum (I) and its response to contact with a large bait (B) after $(a) 12 \mathrm{~d} ;(b) 19 \mathrm{~d} ;(c) 22 \mathrm{~d}$, showing effuse mycelium produced on contact with the bait and thickened connective cord (arrowed); $(d) 27 \mathrm{~d} ;(e) 44 \mathrm{~d}$, showing regression of non-connective mycelium; $(f) 70 \mathrm{~d}$, showing outgrowth of mycelium from bait. Bar represents $4 \mathrm{~cm}$. 

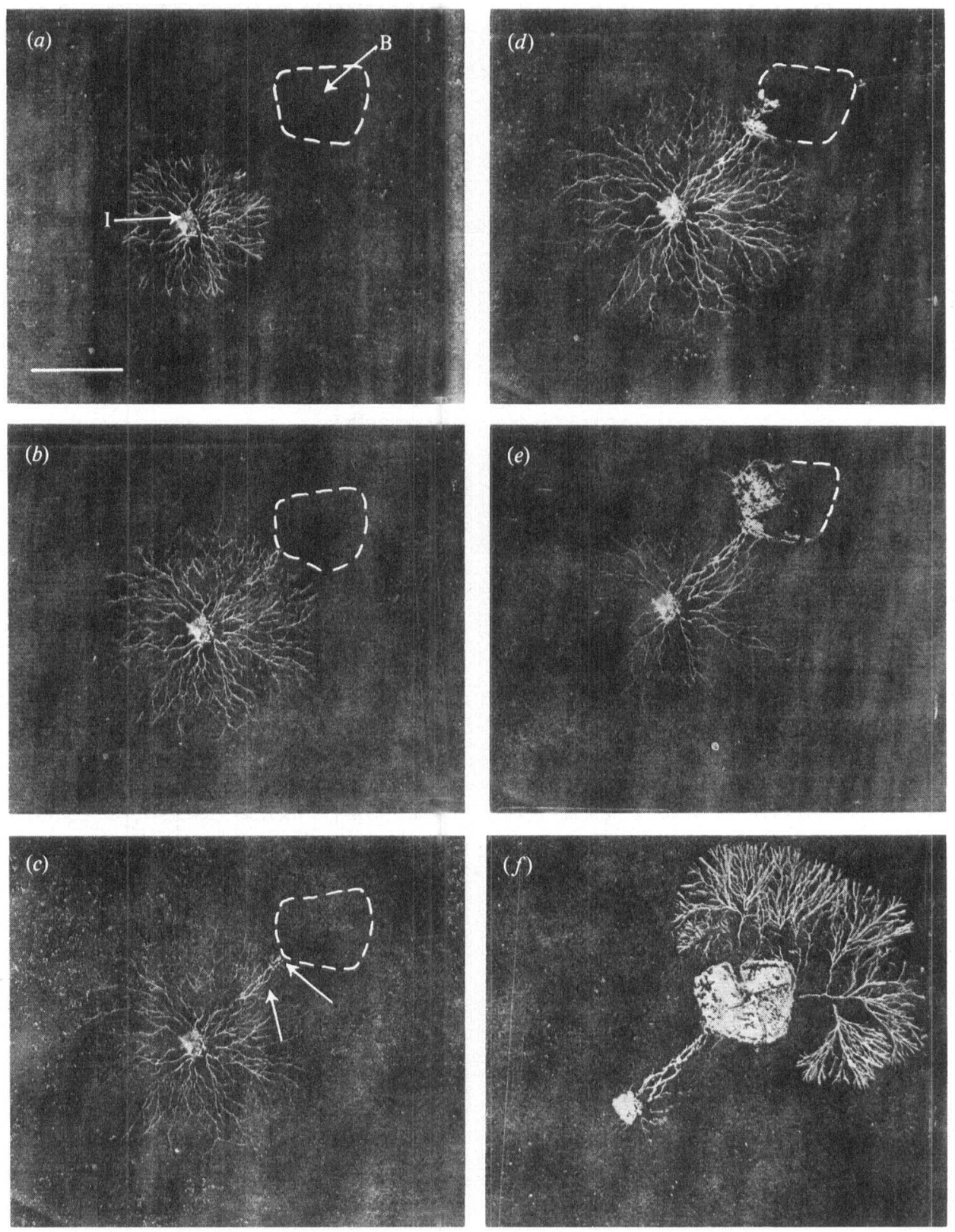

Fig 5. Outgrowth pattern of $P$. velutina from a small inoculum (I) and its response to contact with a large bait (B) after $(a) 8 \mathrm{~d} ;(b) 12 \mathrm{~d}$, showing effuse mycelium at the point of contact with bait (arrowed); (c) $22 \mathrm{~d}$, showing thickened connective cord; (d) $27 \mathrm{~d}$; (e) $44 \mathrm{~d}$, showing curvature and redirected growth of a non-connective cord towards bait (arrowed); $(f) 70 \mathrm{~d}$, showing arrival of redirected cord, regression of other non-connective cords and outgrowth from the bait. Bar represents $4 \mathrm{~cm}$. 


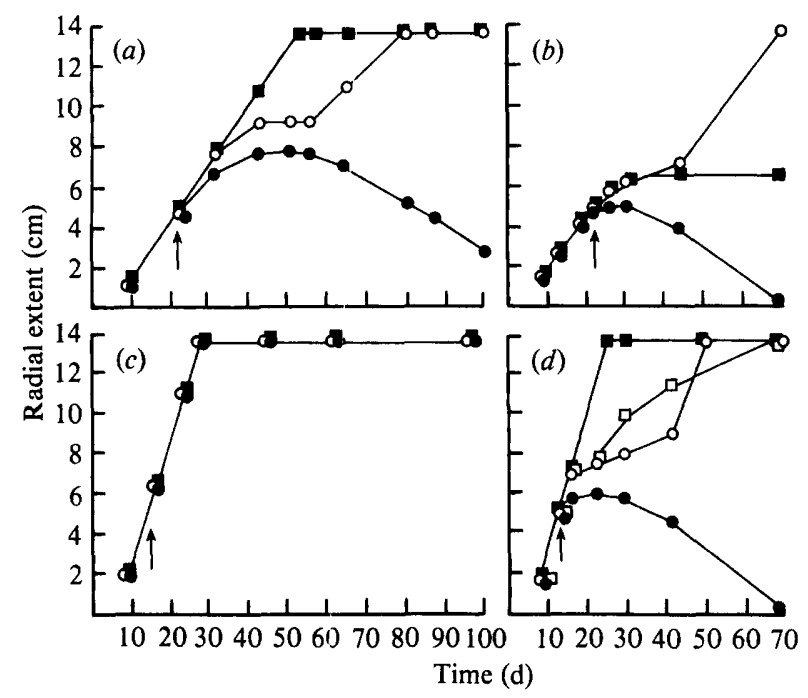

Fig. 6. Collected mean data showing outgrowth of $H$. fasciculare $(a, b)$ and $P$. velutina $(c, d)$ from large $(a, c)$ and small $(b, d)$ inocula along the diagonal between inoculum and baits $(O)$, non-connective mycelium (O), cords which eventually become connective only after $70 \mathrm{~d}$ (Fig. $5 e, f)(\square)$ and controls (a). Error bars are omitted for clarity, but variation between replicates was less than $4 \%$. Arrows indicate time of contact with the bait.

\section{DISCUSSION}

The present observations demonstrate the strikingly different properties of mycelia growing on discontinuously supplied resource units as opposed to under homogeneous conditions. Essentially, these properties may be related to the distinctive demands on the one hand for efficient discovery of nutrient depots and on the other for economical usage and redistribution of resources available to a mycelium interconnecting different depots.

Two types of behaviour may facilitate efficient discovery of nutrient depots (Rayner et al., 1985). The first involves production of sparse exploratory mycelial systems which only develop further once contact with a suitable nutrient base has been made. Evidence for this type of behaviour has been provided by the present study and also for certain cord-forming mycorrhizal fungi by Read (1984). The underlying mechanism is obscure, but may involve establishment of nutrient exchange between food bases: indeed Watkinson (1975) has used the establishment of cords of Serpula lacrimans between separated nutrient agar plugs as a basis for translocation studies.

Secondly, direct growth of hyphae, mycelium or mycelial aggregates may occur towards nutrient sources. Until recently, evidence for such directed growth has mostly been confined to certain water moulds (Saprolegniaceae) (Fischer \& Werner, 1958), but there are now indications of similar mechanisms in some wood-inhabiting fungi (Mowe et al., 1983; Thompson \& Rayner, 1983; Thompson, 1984).

In the present study fairly marked curvature or redirection of connective cords towards the baits was apparent in several cases. However, this was not a consistent observation, and the experiments were also not designed specifically to distinguish between causative factors, be these release of a soluble or a volatile compound from the blocks, or some other local change in microenvironmental conditions. The controls were, however, intended to simulate effects of a discontinuity in the soil system, and the experimental design should also have minimized development of moisure gradients. We have obtained better evidence for directed growth by $H$. fasciculare and $P$. velutina by growing systems over moist, compacted sand, rather than through soil (data not shown). 
Evidence for economic usage and redistribution of resources by mycelium interconnecting resource units was provided by the inhibitory effects of contact with baits on the remainder of the colony margin, by the regression of mycelium originating from the inoculum associated with renewed growth from the bait, and by the differences between outgrowth patterns, particularly by $P$. velutina, using large and small inocula/baits. With respect to the last point, it would obviously be efficient in growth from a small to a large base to reallocate resources to the latter, but not vice versa: this was brought out by the maintenance of the mycelial systems emanating from large inocula, but regression of these from small inocula. It should also be noted that the small inocula used in the present experiments would contain a smaller nutrient supply not only in relation to their volume, but also because they had been incubated with mycelium for a longer time period.

In summary, these observations provide evidence for the corporate nature of mycelial systems and how this facilitates migration between nutrient depots. Analogies with other spatially indeterminate eukaryotic bodies such as stoloniferous plants and myxomycete plasmodia are strong and we think that recognition of this fact could provide a useful basis for understanding fungal behaviour and a fresh impetus for ecological and physiological studies.

This work was supported by a research grant from the Natural Environment Research Council.

\section{REFERENCES}

COOKE, R. C. \& RAYNer, A. D. M. (1984). Ecology of Saprotrophic Fungi. London \& New York: Longman.

DowDING, P. (1976). Allocation of resources, nutrient uptake and release by decomposer organisms. In The Role of Terrestrial and Aquatic Organisms in Decomposition Processes, pp. 169-183. Edited by J. M. Anderson \& A. Macfayden. Oxford: Blackwell Scientific.

DowDING, P. (1981). Nutrient uptake and allocation during substrate exploitation by fungi. In The Fungal Community; Its Organization and Role in the Ecosystem, pp. 621-636. Edited by D. T. Wicklow \& G. C. Carroll. New York: Marcel Dekker.

Fischer, F. G. \& Werner, G. (1958). Die Chemotaxis der Schwarmsporen von Wasserpilzen (Saprolegniaceen). Hoppe-Seyler's Zeitschrift für physiologische Chemie 310, 65-91.

Mowe, G., KInG, B. \& SENN, S. J. (1983). Tropic responses of fungi to wood volatiles. Journal of General Microbiology 129, 779-784.

Rayner, A. D. M., Wattling, R. \& Frankland, J. C. (1985). Resource relations - an overview. In Developmental Biology of Higher Fungi, pp. 1-39. Edited by D. Moore, L. A. Casselton, D. Wood \& J. C. Frankland. Cambridge: Cambridge University Press.

READ, D. J. (1984). The structure and function of the vegetative mycelium of mycorrhizal roots. In The Ecology and Physiology of the Fungal Mycelium, pp. 215-240. Edited by D. H. Jennings \& A. D. M. Rayner. Cambridge: Cambridge University Press.

THOMPSON, W. (1984). Distribution, development and functioning of mycelial cord systems of decomposer basidiomycetes of the woodland floor. In The Ecology and Physiology of the Fungal Mycelium, pp.
185-214. Edited by D. H. Jennings \& A. D. M. Rayner. Cambridge: Cambridge University Press. Thompson, W. \& RAYNER, A. D. M. (1982a). Structure and development of mycelial cord systems of Phanerochaete laevis in soil. Transactions of the British Mycological Society 78, 193-200.

Thompson, W. \& Rayner, A. D. M. (1982b). Spatial structure of a population of Tricholomopsis platy. phylla in a woodland site. New Phytologist 92, 103 114.

Thompson, W. \& RaYner, A. D. M. (1983). Extent, development and function of mycelial cord systems in soil. Transactions of the British Mycological Society 81, 333-345.

TrincI, A. P. J. (1978). The duplication cycle and vegetative development in moulds. In The Filamentous Fungi, Vol. 3. Developmental Mycology, pp. 132163. Edited by J. E. Smith \& D. R. Berry. London: Edward Arnold.

TrincI, A. P. J. (1979). The duplication cycle and branching in fungi. In Fungal Walls and Hyphal Growth, pp. 319-358. Edited by J. H. Burnett \& A. P. J. Trinci. Cambridge: Cambridge University Press.

WATKINSON, S. C. (1975). The relation between nitrogen nutrition and formation of mycelial strands in Serpula lacrimans. Transactions of the British Mycological Society 64, 195-200.

WATKInson, S. C. (1984). Morphogenesis of the Serpula lacrimans colony in relation to its function in nature. In The Ecology and Physiology of the Fungal Mycelium, pp. 165-184. Edited by D. H. Jennings \& A. D. M. Rayner. Cambridge: Cambridge University Press. 